Bangladesh Journal of Anatomy July 2012, Vol. 10 No. 2 pp 50-56

\title{
Presence of Cystic Artery in the Calot's Triangle and Its Relation with Common Hepatic Duct - a Postmortem Study
}

\author{
Md. Khalilur Rahman', Selina Anwar²
}

\begin{abstract}
Introduction: Most common disease of liver and biliary tree is cholelithiasis which needs surgical intervention. Safe execution of traditional cholecystectomy or laparoscopic surgery needs proper knowledge of the origin, course, branching pattern of the cystic artery and its relation with common hepatic duct. This study was aimed to find the presence of cystic artery in the Calot's triangle and its relation with common hepatic duct to prevent any iatrogenic complications especially for newer surgeons in this field.

Materials and Methods: This study was done on 60 postmortem gallbladder collected from postmortem dead bodies under the guidance of Forensic Medicine department of Rangpur Medical College, Rangpur. After collection of the specimen, the boundary of the Calot' triangle was identified and course of the cystic artery was observed whether it was passing through the triangle or not. The relation of the cystic artery with the common hepatic duct was also noticed.
\end{abstract}

Results: It was found from the result of the present study that out of 60 cases cystic artery was found as a content of Calot's triangle in 58 (96.65\%) cases. Regarding the relations of the cystic artery, out of 60 specimens, in 54 cases (90\%) cystic arteries were observed to pass behind the common hepatic duct. In four cases (6.67\%) cystic artery were found crossing over the common hepatic duct and in two cases (3.33\%), cystic artery were found crossing below the cystic duct.

In one cases, branches of cystic artery (superficial and deep branch) was found. In every specimen a Calot's node was found within the Calot's triangle.

Discussions: The result of the present study was compared with other workers. Though many of the workers found similar results regarding the course of the cystic artery through the Calot' triangle but some workers found higher number of cystic artery passing outside the triangle. Also higher percentage of cystic artery passing over the common hepatic duct was found by many workers than the present study.

Key words: Cystic artery, Calot's triangle, Hepatic duct

\section{Introduction}

Liver and billiary diseases are the most common health problem throughout the world as well as in Bangladesh. The most common biliary diseases are cholelethiasis. Up to $25 \%$ of all Bangladeshi people have gallstones ${ }^{1}$. A traditional cholecystectomy is most commonly performed from the infundibulum to the fundus as no medical treatment is still available ${ }^{2}$. Now a days laparoscopic cholycystectomy replaces the open

1. Associate Professor, Department of Anatomy, Shahid Ziaur Rahman Medical College, Bogra.

2. Professor, Department of Anatomy, Rangpur Medical College, Rangpur

Correspondence: Dr. Md. Khalilur Rahman surgical method. During operation surgeons have to identify the cystic duct and artery properly before ligation. Uncontrolled bleeding from the cystic artery and its branches is a serious problem that may increase the risk of intraoperative lesions to vital vascular and biliary structures. On laparoscopic visualization anatomic relations are seen differently than during conventional surgery. The origin and course of the hepatic artery and its relation to the cystic duct and branching pattern to the gall bladder studied by many workers, showed varied results. Most of them found the cystic artery as a content of Calot's triangle. The triangle of Calot is one of the most variable regions of abdomen in terms of 
anatomy. The Calot's triangle, named for Jean Francois Calot (1891 cited by Houbrich) ${ }^{3}$ is an isosceles triangle with the common hepatic duct as its base, the inferior edge of the cystic duct and the superior border to the cystic artery as its sides. The cystic artery normally passes through the triangle.

Many other workers describe this triangle as the hepatobiliary triangle or cystohepatic triangle, an anatomical space bordered by the common hepatic duct medially, the cystic duct inferiorly and the liver superiorly (inferior surface of segment $v$ of the liver) $4,5,6,7$.

Specht ${ }^{4}$ and Sanjay ${ }^{8}$ was described about Calot's triangle that its contents usually include the right hepatic artery, the cystic artery, the cystic lymph node (of Lund), connective tissue, and lymphatics. Occasionally it may contain accessory hepatic ducts and arteries. The left (or medial) boundary of the triangle formed by the bile duct is the most important structure, which needs to be safe guarded during cholecystectomy. So proper knowledge of the Calot's (hepatocystic) triangle's anatomic structures under the conditions of laparoscopic visualization as well as traditional cholecystectomy would be important for the safe execution of any operative procedure. Specifically in the context of a cholecystectomy, it has been recognized since long that misinterpretation of normal anatomy as well as the presence of anatomical variations contribute to the occurrence of major postoperative complications especially biliary injuries ${ }^{9}$. Such injuries in turn can cause significant morbidity and occasionally even mortality. Also there is much variation in the origin, course, and mode of distribution of the cystic artery to the gallbladder which a surgeon must have to face during open cholecystectomy and laparoscopic cholecystectomy.

With the above rationale keeping in mind this study was aimed to determine the variations regarding the position of the cystic artery in the Calot's triangle and its relation with the cystic duct in Bangladehi people which would help the surgeons in proper and safe performance of laparoscopic as well as traditional cholecystectomy and also to minimize iatrogenic injury.

\section{Materials and methods:}

The present study was carried out on 60 (sixty) post mortem gallbladder collected from Bangladeshi adult people. Ranges of age of these people were between 20 and 65 years. Samples (human gallbladder with cystic duct) were collected as block dissection of liver along with cystic artery, hepatic artery, hepatic duct, cystic lymph node, common hepatic duct (CHD), common bile duct (CBD) etc. from the unclaimed dead bodies from the post mortem examination room of the Department of Forensic Medicine of Rangpur Medical College, Rangpur. Time of collection was from July, 2008 to June, 2009. The specimens which were apparently healthy collected from the cadavers as early as possible (usually within 24 to 36 hours of death) without any apparent physical signs of putrefaction. Gall bladders which were grossly injured, putrefied gallbladder, diseased gallbladder (fibrosed gallbladder, distended gallbladder etc.), gallbladder of poisoning cases, and gallbladder of decomposed body were excluded from the present study.

Soon after collection, the specimens were brought to the laboratory of the Department of Anatomy, Rangpur Medical College, Rangpur for study.

Each specimen was gently washed in tap water on a dissection tray. Blood and Blood clots were removed as far as possible. After removal of loose areolar tissue, the Calot's triangle was exposed. The cystic nodes, cystic artery was identified. Calot's triangle and its content documented by Sony camera-DSC-S750.

Each specimen was kept in a plastic jar and duly tagged with an identified number along with approximate age and sex and date of collection. Afterward the specimens were fixed with $10 \%$ formol saline solution for histological study.

\section{Parameters:}

1. Observation of the Calot's triangle with its contents 
a) Location of Calot's triangle.

b) Content of Calot's triangle (especially cystic artery)

c) Number of Calot's node.

1. Relation of the cystic artery with the common hepatic duct.

\section{Results}

The boundary of the Calot's triangle was observed as a pyramidal shaped area bounded by the common hepatic duct medially, cystic duct laterally and liver superiorly (Fig.-1) The Calot's triangle's size was different in specimen to specimen. Out of 60 specimens, the cystic artery was passing within Calot's triangle in 58 specimens $(96.65 \%)$ but in 2 specimens $(3.35 \%)$ the cystic artery was outside the Calot's triangle. In all cases single cystic artery was found.

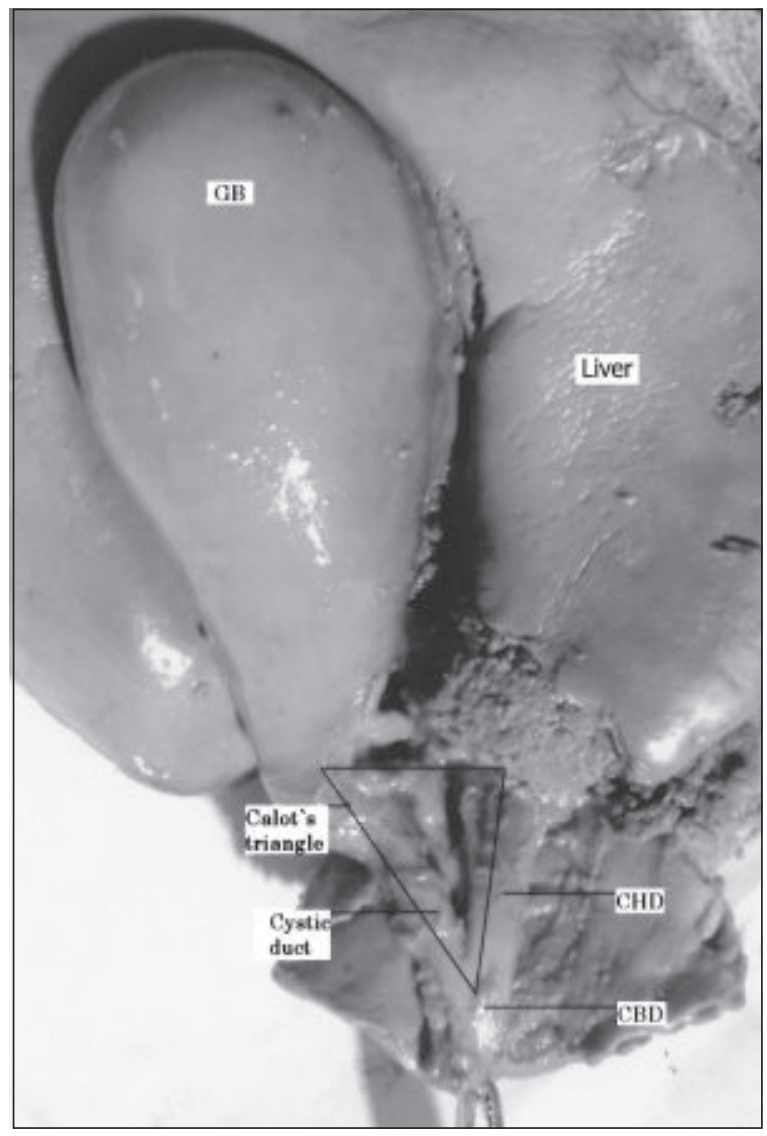

Fig.-1: Photograph showing the triangle which correspond with the Calot's triangle boundary
Based on the observation of Calot's triangle, the anatomic variations of the cystic artery can be classified into two groups:

a) Group 1-cystic artery passing within Calot's triangle-58 cases-96.65\%

b) Group II-the cystic artery situated outside Calot's triangle -2 cases $-3.35 \%$

Regarding the relations of the cystic artery (Table 1), out of 60 specimens, in 54 cases (90\%) cystic arteries were observed to pass behind the common hepatic duct, (Fig.-2). In four cases $(6.67 \%)$ cystic artery were found crossing over the common hepatic duct, (Fig.-3) and in two cases (3.33\%), cystic artery were found crossing below the cystic duct (Fig.-4)

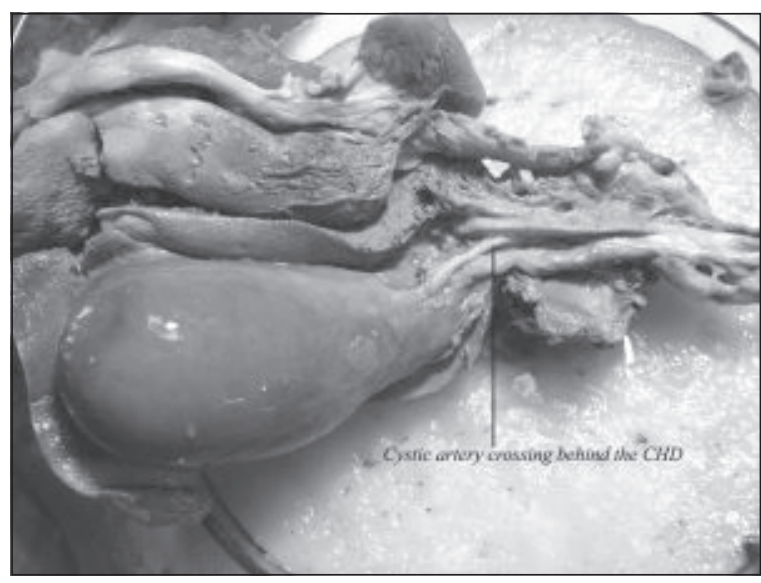

Fig.-2: Photograph showing the cystic artery crossing behind the common hepatic duct.

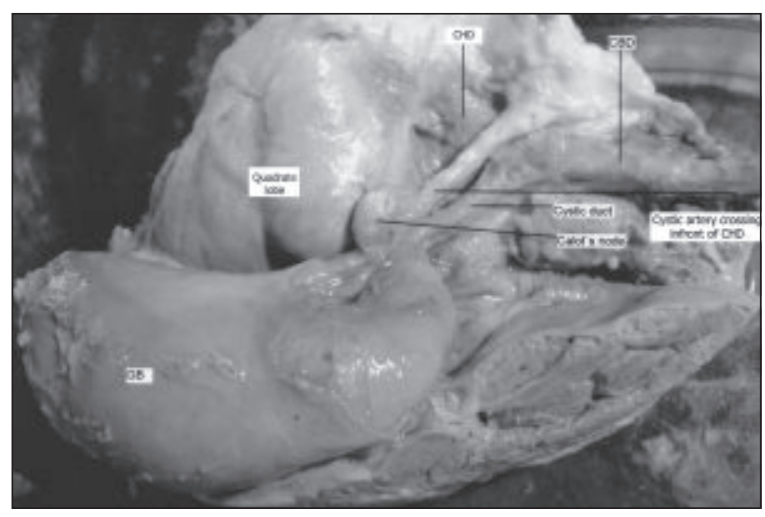

Fig.-3: Photograph showing the cystic artery crossing over the common hepatic duct. 


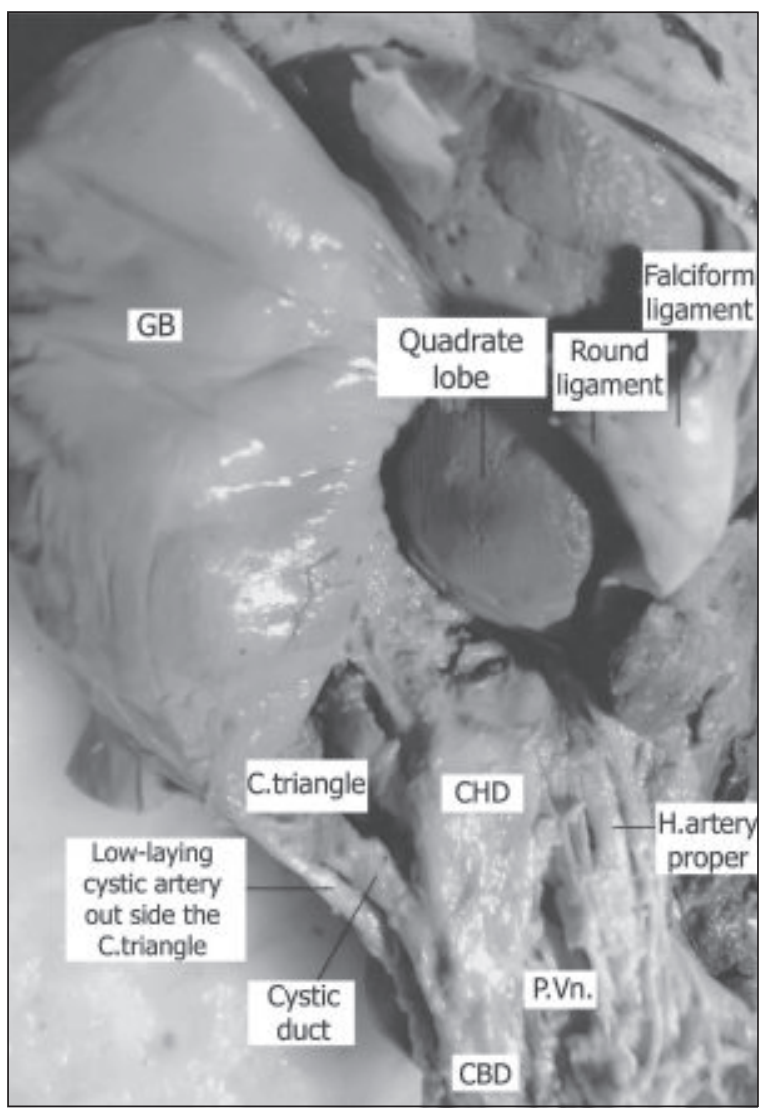

Fig.-4: Photograph showing the cystic artery crossing below the cystic duct (low lying cystic artery).

In one cases, branches of cystic artery (superficial and deep branch) was found. (Fig. 5).

\section{Table-I}

Relation of the cystic artery with the common hepatic duct and cystic duct

\begin{tabular}{lcc}
\hline Cystic artery & $\begin{array}{c}\text { Specimen Percentage } \\
\text { No (N) }\end{array}$ \\
\hline Crossing behind the CHD & 54 & $90 \%$ \\
Crossing over the CHD & 4 & $6.67 \%$ \\
Crossing below the cystic duct & 2 & $3.33 \%$ \\
\hline
\end{tabular}

In every specimen a Calot's node was found within the Calot's triangle (Fig 3)

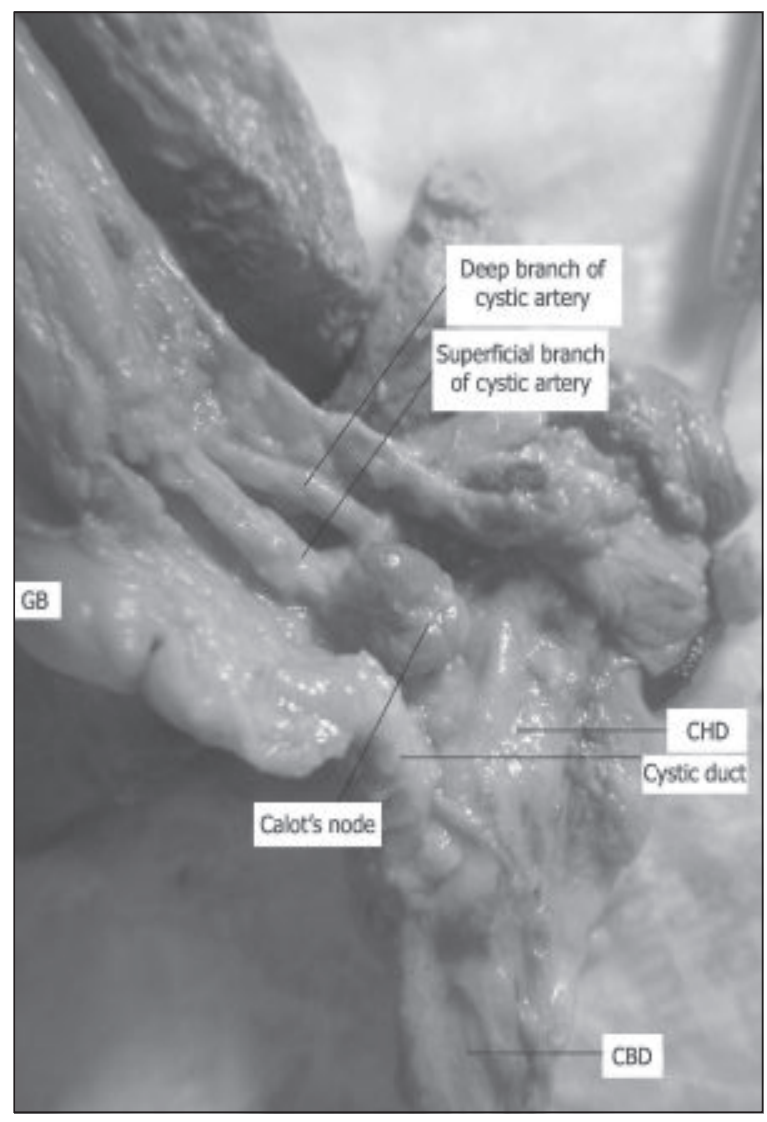

Fig.-5: Photograph showing the superficial and deep branches of the cystic artery.

Table-II

Presence of cystic artery within the Calot's triangle

\begin{tabular}{|c|c|c|c|}
\hline \multirow{2}{*}{$\begin{array}{l}\text { Author's } \\
\text { name/URL }\end{array}$} & \multicolumn{3}{|c|}{ Cystic artery } \\
\hline & & $\begin{array}{l}\text { hin the Calot's } \\
\text { triangle }\end{array}$ & $\begin{array}{c}\text { Outside the } \\
\text { Calot's triangle }\end{array}$ \\
\hline Balija $^{5}$ & Norma & lly passes $73.5 \%$ & $\% \quad 4.5 \%$ \\
\hline Suzuki ${ }^{6}$ & & $76.6 \%$ & $11.1 \%$ \\
\hline Flisinski ${ }^{10}$ & & $97.06 \%$ & $2.94 \%$ \\
\hline Ding ${ }^{11}$ & & $85.5 \%$ & $13 \%$ \\
\hline Khalii ${ }^{12}$ & & $98 \%$ & $2 \%$ \\
\hline Chen ${ }^{14}$ & & $86.1 \%$ & \\
\hline Saidi ${ }^{16}$ & & & $3.9 \%$ \\
\hline Myint \& Thuz & & $90 \%$ & \\
\hline Current stud & y 2010 & $96.65 \%$ & $3.35 \%$ \\
\hline
\end{tabular}


Bangladesh J. Anat. 2012; 10(2) : 50-56

Table-III

Variation in the course of cystic artery.

\begin{tabular}{lccc}
\hline $\begin{array}{l}\text { Authors } \\
\text { name/ URL }\end{array}$ & $\begin{array}{c}\text { Crossing } \\
\text { behind } \\
\text { the CHD }\end{array}$ & $\begin{array}{c}\text { Crossing } \\
\text { over } \\
\text { the CHD }\end{array}$ & $\begin{array}{c}\text { Crossing } \\
\text { below the } \\
\text { cystic duct }\end{array}$ \\
\hline Balija $^{5}$ & & & $4.9 \%$ \\
Ibingira $^{9}$ & $67.66 \%$ & $29.40 \%$ & $2.94 \%$ \\
Flisinski $^{10}$ & $72.7 \%$ & $11.8 \%$ & \\
Chen $^{14}$ & $46.1 \%$ & $45.1 \%$ & \\
Saidi $^{16}$ & $76 \%$ & $24 \%$ & \\
Moore and Dalley $^{18}$ & & $4 \%$ & \\
Ayyaz $^{19}$ & & $6.67 \%$ & $3.33 \%$ \\
Current study (2010) & $90 \%$ & 6 &
\end{tabular}

\section{Discussions:}

The performance of a safe cholecystectomy depends on thorough knowledge about the normal anatomy and anatomical variations that may contribute to the occurrence of major postoperative complications. The famous triangle originally described by Calot in $1891^{3}$, usually contain the right hepatic artery, the cystic artery, the cystic lymph node, connective tissue and lymphatics. During cholecystectomy this triangle is dissected to identify the cystic artery and cystic duct before ligation and division.

The gallbladder is supplied by the cystic artery. There are many variations in the number, origin and position of the cystic artery observed by different workers. In our study its number was single in all cases but double cystic artery was found by Balija ${ }^{5}$ in $21.1 \%$ cases and by Suzuki ${ }^{6}$ in $11.1 \%$ cases, Fliniski ${ }^{10}$ $2.29 \%$ cases

Regarding the position of the cystic artery, it was found in our study that in $96.65 \%$ cases the cystic artery was passing through the Calot's triangle. Table II shows the cumulative findings regarding the variations of the presence of the cystic artery in the Calot's triangle by different authors. From this table it could be assumed that the position of the cystic artery within the Calot's triangle found by different workers varied to some extent. Though some have similar results but percentage regarding the position of the artery outside the triangle was high in the study done by Suzuki ${ }^{6}$ and Ding ${ }^{11}$. Artery traverses the triangle almost in its center ${ }^{6}$. Before dividing into the superficial and deep branches at the superior aspect of the gallbladder neck, the cystic artery travels superiorly to the cystic duct and produces 2 to 4 minor branches, known as Calot's arteries that supply part of the cystic duct and cervix of the gallbladder

Regarding the relation of the artery, in 54 cases $(90 \%)$ the artery passes below the CHD, in 4 cases $(6.67 \%)$ the artery was found crossing over the CBD and in 2 cases (3.33\%) it was found crossing below the cystic duct.

In the last cases this type of artery was said to be low lying cystic artery by Balija $^{5}$ and Khalil ${ }^{12}$. According to them when a single cystic artery arises from gastroduodenal artery it forms a configuration known as low-lying cystic artery, as it passes inferior to the cystic duct through the cholecystoduodenal ligament, and therefore remains outside the hepatobiliary triangle ${ }^{5,12}$. The cystic artery not uncommonly runs in front of the common bile duct 13. Table III shows the cumulative findings regarding the variations of the relation of the cystic artery with the CBD and cystic duct by different authors. From this table it could be assumed that the finding of Saidi is much different than all other workers. Also the percentage of cystic arteries crossing over the CBD were also high found by Flisinki ${ }^{10}$, Ibingira ${ }^{9}$, Chen et al ${ }^{14}$.

In every cases there is a lymph node termed as Calot's node was found in the Calot's triangle. Lymph node was also found by Sujuki 6 .

Balija ${ }^{5}$ classified the cystic artery in relation to the hepatobiliary triangle: Group I designates a cystic artery situated within the hepatobiliary triangle on laparoscopic visualization. This group included three types: (1) normally lying cystic artery, (2) most common cystic artery variation, manifesting as its doubling and (3) the cystic artery originating from the aberrant right hepatic artery, Group II designates a cystic artery that could not be found within the hepatobiliary triangle on laparoscopic dissection. This group included two types of variation: (1) cystic artery originating from the gastro duodenal artery and (2) cystic artery originating from the left hepatic artery. 
Flisinski ${ }^{10}$ reported that the cystic artery was originating from the gastroduodenal artery in $2.94 \%$ cases.

According to Ibingira ${ }^{9}$, the cystic artery usually is the branches from the right hepatic artery and passes behind the common hepatic duct to reach the gallbladder. In $15 \%$ of the cases the right hepatic artery and or the cystic artery cross in front of the common hepatic duct.

Flisinki ${ }^{10}$ reported that the cystic artery most frequently $(67.66 \%)$ runs behind the common hepatic duct, rarely $(29.40 \%)$ over the common hepatic duct and most rarely $(2.94 \%)$ on the left side of the cystic duct.

Khali ${ }^{12}$ studied on 60 post mortem human livers collected from Bangladeshi cadavers of both sex (male-40, female-20). In his study, the so-called typical origin of the cystic artery from right hepatic artery was $90 \%$ and in $10 \%$ cases it was found to arise from other sources. $2 \%$ from gastro duodenal artery (low-lying cystic artery) passes inferior to the cystic duct.

In our study the frequency of the anatomical variations regarding the cystic artery within the Calot's triangle was observed carefully because this changeability may lead to one of the most dangerous intrapoerative complications: bleeding in the hepatobiliary triangle.

Unusual variations of the cystic artery may cause risk in surgery. Knowledge of anatomic variations of the cystic artery will be useful for decreasing uncontrollable cystic artery hemorrhage and avoiding extrahepatic bile duct injury specially in case of younger surgeons who're not yet familiar with the handling of an anatomically abnormal cystic blood supply need to be more aware of the precise anatomy of the extrahepatic biliary tree.

\section{References}

1. Wikipedia contributors. Gallbladder [Internet]. Wikipedia, The Free Encyclopedia; $2008 \mathrm{Nov}$ 11, 02:49 UTC [cited 2008 Nov 13]. <http:// en.wikipedia.org/w/index.php?title= Gallbladder\&oldid=25101935
2. Neri $\mathrm{V}$, Ambrosi A, Fersini A, Tartaglia $\mathrm{N}$ and Valentino TP. "Antegrade dissection in laparoscopic cholecystectomy". JSLS : Journal of the Society of Laparoendoscopic Surgeons / Society of Laparoendoscopic Surgeons. 2007; 11(2): 225-8.

3. Haubrich, W S 2002, Calot of the triangle of Calot, Gastroenterology, 2000; 123(5): 144 <http://www.gastrojournal.org/article/ PIIS0016508502003256/fulltext>

4. Specht, MJ, Calot's triangle, JAMA, 1967; 200(13): 1186.

5. Balija, M, Huis, M, Nikolic, V, and Stulhofer, M, Laparoscopic visualization of the cystic artery anatomy, World J Surg, 1999; 23(7): 703-07. http://www.ncbi.nlm.nih.gov/pubmed/ 10390590

6. Suzuki.M, Akaishi.S, Rikiyama.T, Naitoh.T, Rahman.M, Matsuno.S. Laparoscopic cholecystectomy, Calot's triangle, and variations in cystic arterial supply. Journal Surgical Endoscopy.NewYork. Springer. 2000 February; 14(2): 141-44.

7. Datta.A.K. Essentials of Human Anatomy, Part-I. Mumbai. India. $6^{\text {th }}$ ed Current Books International. 2002; 266-67.

8. Sanjay N. Anatomy relevant to cholecystectomy. Journal of Minimal Access Surgery. 2005; 1(2): 53-58. <http://www.bioline.org.br/request? ma05011\#t1>

9. Ibingira, C.B.R. Groos Anatomical variations and congenital anomalies of surgical importance in hepatobiliary surgery in Uganda. East and Central African Journal of Surgery, 2006;12(1): 93-98. http://www.bioline. org.br/ request?js07017

10. Flisinski P, Szpinda M, Flisinski M. The cystic artery in human foetuses. Folia morphologica 2004;63(1):47-50.

11. Ding.Y.M, Wang.B, Wang.W, Wang.P, Yan.j. New classification of the anatomic variations of cystic artery during Laparoscopic cholecystectomy. World journal of Gastroenterology. 2007;13(42):5629-34. 